\title{
La Demanda del Santo Grial (1515)
}

\author{
José Ramón Trujillo (InTRoducción, Edición y nOtas)
}

Alcalá de Henares, Servicio de Publicaciones de la Universidad de Alcalá-IEMSO

(colección Los Libros de Rocinante, n.o 33), 2017. LVIII + 289 pp.

Aparece este volumen como número 33 de la colección de la prestigiosa colección de libros de caballerías castellanos Los Libros de Rocinante que, desde el año 1997, con su primera publicación, el Platir, dirigen los profesores Carlos Alvar y José Manuel Lucía Megías, y cuya labor continúan, desde el 2015, en el marco del nuevo Instituto de Estudios Medievales y Siglo de Oro "Miguel de Cervantes" y la colaboración del Servicio de Publicaciones de la Universidad de Alcalá (UAH). El profesor José Ramón Trujillo, reconocido especialista en traducción medieval y de los Siglos de Oro, nos presenta la esperada primera edición crítica de la Demanda del Santo Grial castellana, junto con un extenso y documentado estudio introductorio y una amplia bibliografía especializada. Se trata del último texto artúrico hispánico que permanecía sin edición moderna, cuyo estudio y preparación habían sido abordados previamente en su tesis doctoral
(2004), a partir del único ejemplar conservado del impreso infolio publicado en 1515 .

El estudio introductorio, que abarca las primeras 58 páginas del volumen, se estructura en seis apartados: 1. El santo Grial en la península ibérica; 2 . La materialidad de los textos: de las traducciones manuscritas a los impresos del siglo XVI; 3. Modificaciones en el texto castellano; 4. Los contenidos y estructura de la Demanda; 5. La Demanda entre los libros de caballerías; y 6. Criterios de edición. El primer apartado ofrece un amplio encuadre de La Demanda del Santo Grial como parte esencial del extenso corpus de las aventuras artúricas, así como su evolución y recepción peninsular. El texto de los impresos castellanos conservados de 1515 y 1535 proviene de una sucesión de reelaboraciones que tienen como arquetipo una traducción medieval de finales del siglo XIII. Su origen en última instancia es una versión de la Queste del 
Saint Graal en prosa (hoy perdida), escrita en francés, y que incorpora la Mort Artu, es decir, aglutina los episodios de los caballeros de la Mesa Redonda en busca del Santo Grial con la muerte del rey Arturo, que supone el fin del reino de Londres y el ocaso del mundo venturoso de la caballería. En las primeras décadas del siglo XIII, la tradición en prosa del ciclo artúrico se conformó en francés, mediante refundiciones y reescrituras de textos precedentes en verso y motivos tradicionales, en cinco ramas (versión conocida como la Vulgata): la Estoire del Saint Graal, la Estoire de Merlin, el Lancelot, la Queste del Saint Graal y la Mort Artu. La versión Pseudo-Boron o Post-Vulgata de la que parte la Demanda del Santo Grial difiere notablemente de la redacción Vulgata. En primer lugar, presenta un cambio en cuanto a la interpretación temática sobre la que giran las aventuras, ya que el Pseudo-Boron deshace el double sprit religioso y cortés, con una clara división entre las aventuras corteses de los caballeros y la aventura espiritual del Grial. En segundo lugar, se produce un cambio estructural, reduciendo sus ramas de cinco a tres: José de Arimatea (o Estoire del Saint Graal), Baladro del sabio Merlín y la propia Demanda del
Santo Grial, que integra la Muerte de Arturo.

Las modificaciones realizadas en el original francés perdido del nuevo ciclo y la labor del traductor castellano, que comparte el espíritu de la traducción de la época, unido a la formación intelectual del individuo y del organismo o sociedad a la que perteneció, fueron valoradas negativamente por los especialistas de la primera mitad del siglo XX (Gaston Paris, Pauphilet, Bohigas y Lida de Malkiel, entre otros) como elementos que dañaban el conjunto de la obra, colocando la versión peninsular en un nivel artístico-literario inferior al de la Vulgata francesa. Según esta perspectiva, las alteraciones generan incoherencias y destruyen el elevado simbolismo espiritual de la Vulgata, otorgando excesivo espacio a los episodios caballerescos. A partir de los trabajos de Eugène Vinaver y Fanni Bogdanow, que estudiaron estas modificaciones no como una deturpación, sino como una evolución de los patrones y gustos literarios, se revalorizó la originalidad de la nueva versión del ciclo, que refunde los motivos artúricos anteriores con la clara intención de crear un ciclo más coherente y original, para alumbrar el libro artúrico total. Conocido anteriormente 
como Pseudo-Boron, pasó a denominarse al nuevo conjunto ciclo Post-Vulgata o Roman du Graal.

El segundo apartado estudia los testimonios conservados y ofrece un rastreo en profundidad del peregrinar de los ejemplares por bibliotecas, así como las menciones observables en otros textos. De las aventuras del ciclo Pseudo-Boron/ Post-Vulgata se conservan, en castellano, dos impresos de la primera parte o Baladro del sabio Merlín (Burgos 1498 y Sevilla 1535), otros dos de La Demanda del Santo Grial propiamente dicha (Toledo 1515, Sevilla 1535), tres fragmentos abreviados de cada una de las ramas (incluyendo el José de Arimatea) dentro de un manuscrito religioso (ms. 1877 de la Biblioteca Universitaria de Salamanca) y un resumen en el Libro de las bienandanzas e fortunas, de García de Salazar, de finales del siglo XV. A ello se suman como precedentes un manuscrito portugués conservado en la Biblioteca Nacional de Austria y algunos fragmentos manuscritos franceses. Es difícil conocer la extensión del ciclo en Castilla. Tenemos constancia de que la Reina Católica, Isabel I, tuvo en sus bibliotecas del Alcázar y de Granada una Demanda junto con un Merlin y una Ystoria de Laçarote, que Felipe II ordenaría trasladar al castillo de Simancas. También disponemos de varias menciones al texto y a la presencia de ejemplares de mano o impresos en diversas bibliotecas nobiliarias, desde su llegada a la península y hasta el siglo XIX, en que varios ejemplares salen de España. Seguramente circularon muchos más manuscritos e impresos de los que se han conservado, por lo que es difícil reconstruir el itinerario de los textos. Lo seguro es su influencia decisiva en la narrativa de ficción castellana del siglo XIV, a la que ofrece un modelo didáctico cortés en obras como el Libro del caballero Zifar o en el primitivo Amadís de Gaula.

El texto castellano más completo conservado en castellano se conserva en el impreso infolio publicado en Toledo en 1515 por Juan de Villaquirán, del que existe una única copia en la British Library (G 10242) que había pasado a formar parte de la conocida colección Greenville en el British Museum, procedente de la Herber's Library. Forma un volumen facticio, encuadernado en cuero sobre cartón, imitación de una encuadernación francesa del siglo XVIII con el escudo de Thomas Greenville, junto con un ejemplar del Baladro de 1535. El texto se reeditó como 
La demanda del Sancto Grial; e de los fechos del muy esforçado Galaz, en un impreso castellano infolio (Sevilla: s.n., 1535), sin nombre de impresor, pero atribuible a las prensas de Juan Varela de Salamanca, formando unidad con un Baladro impreso diferente del de 1498. Se trata de la versión más extendida a través de la edición llevada a cabo por Bonilla y Sanmartín en 1907. De este impreso, muy actualizado lingüísticamente, se conservan varios ejemplares, unidos a la edición del Baladro de 1535: Biblioteca Nacional de España (Madrid), Bibliothèque Nationale de France (París), Biblioteca Histórica Marqués de Valdecilla (Universidad Complutense de Madrid), National Library of Scotland (Edimburgo), Herzog-August Bibliothek (Wolfenbüttel), Newberry Library (Chicago) y en la University of Illinois (Urbana Champaign).

En el tercer apartado el profesor Trujillo estudia y ejemplifica las modificaciones textuales producidas, tanto durante el proceso de traducción como en las fases de refundición y a su paso por la imprenta renacentista, diferenciando los diferentes momentos de recepción del texto. Las alteraciones desarrollan en general un fuerte mensaje moral y didáctico propio de las lecturas de ocio cortesano, entre las que destacan la casi eliminación de la historia de Lanzarote y la disminución de las aventuras amorosas, así como una amplificatio del nacimiento incestuoso de Morderec, hijo de Arturo, y cómo este hecho es el que provoca la destrucción del reino y el fin del mundo caballeresco. Se destaca en el apartado la importancia del valor religioso y su recepción didáctica, que a menudo olvida la crítica, así como la intervención sobre los motivos maravillosos y el resaltado de los puramente caballerescos, lo que conduce a una notable modificación estructural y a un espíritu que se acerca progresivamente al del género editorial de los libros de caballerías, que en sus definición entre los siglos XV y XVI se apoya decisivamente en la publicación del Amadís y los textos artúricos (Tristán, Merlín, Demanda).

Los apartados 4 y 5 analizan la estructura y su valor simbólico, así como el espíritu resultante, que permite al impresor y los lectores incluirlo de forma destacada entre los libros caballerescos renacentistas. En cuanto a la estructura de la Demanda, esta queda organizada en tres partes. Una primera en la que se narran las aventuras de los caballeros Erec, Iván y Galván, 
que muestran una clara diferencia moral y espiritual con respecto a las aventuras del caballero escogido, Galaz, hijo de Lanzarote, en el que se concentrarán las gloriosas hazañas de su padre, de Perceval, $y$ de Boores, en antiguas versiones de la Vulgata y Post-Vulgata. Erec, llevará su principal virtud, la sinceridad, hasta las últimas consecuencias (véase el sentido didáctico de cada uno de los caballeros terrenales en oposición a la divinidad de Galaz), conduciéndolo a los brazos de la muerte. En la segunda parte se produce un paralelismo entre las aventuras del caballero santo, Galaz, y el caballero pagano, $\mathrm{Pa}$ lomades. Mientras que el hijo de Lanzarote irá en busca del Santo Grial, cuya consecución supondrá alcanzar la cima de la caballería cristiana, Palomades, el mejor caballero pagano, se aventurará en su equivalente terrenal: encontrar y derrotar a la Bestia Ladradora. La conversión de Palomades por intercesión de Galaz acabará convirtiéndose en una alta aventura previa antes de conseguir el Santo Vaso. Las acciones de Galaz subrayan la influencia de los principios cistercienses sobre el texto: la castidad, la humildad y la piedad. Estas características crean un nuevo tipo de caballero que se distancia de los prototipos precedentes; de ahí que Lanzarote, considerado el mejor caballero del mundo, no pueda alcanzar el Grial y deje paso a su hijo, pues sus amoríos adúlteros con Ginebra son una tacha moral imborrable. Por último, una tercera parte que consiste en el fin del mundo de la caballería artúrica debido a la guerra civil entre linajes y de los caballeros afines al rey Arturo y los de su hijo incestuoso Morderec, que acaba trágicamente con la muerte de ambos.

Como se ha dicho, el trabajo de edición científica toma como punto de partida el texto castellano de 1515 , sobre el que se opera aclarando lugares críticos, errores y erratas, a partir del resto de testimonios existentes en francés, portugués y castellano. La edición de un texto medieval, proveniente de diferentes traducciones y refundiciones a lo largo de más de dos siglos, requiere del editor un trabajo filológico minucioso e intensivo: desde el tratamiento de los numerosos sinsentidos textuales, omisiones, adiciones y alusiones propios de la intertextualidad, que requieren de una necesaria elucidación para la correcta comprensión del texto; hasta la regulación de la toponimia y los antropónimos y franceses, una cantidad innume- 
rable de personajes, lugares y realidades con numerosas variantes y deturpaciones, que fácilmente podían inducir a confusión al lector de la época. La edición forma parte de la colección Los Libros de Rocinante, que tiene como fin homogeneizar el amplio corpus textual de los libros de caballerías renacentistas y que, entre otras normas, exige la omisión de notas al pie de página y la presentación de un texto corrido que incluya las correcciones. Esta dificultad, agravada en el caso de las omisiones, lagunas y la variación onomástica, se salva con el envío al lector desde el lugar crítico en el texto hacia diferentes puntos del profundo estudio introductorio.

En conclusión, esta edición de La Demanda del Santo Grial merece el elogio por su novedad, al tratarse del único texto castellano que permanecía sin edición moderna, por la extrema dificultad de la tarea y por el brillante resultado. Además de responder a las necesidades de los lectores especializados, el volumen ofrece al lector la posibilidad de disfrutar de una lectura sin trabas y de apreciar los verdaderos valores e intenciones de la imitatio, amplificatio e inventio obradas sobre la materia. Por otra parte, disponer de un texto fiable y accesible, abre numerosas vías de trabajo y facilitará a los investigadores y especialistas la consulta, la cita y el cotejo con otros textos y versiones. Finalmente, el extenso estudio, ampliado con la nutrida bibliografía que aporta, va más allá del tradicional estado de la cuestión y brinda una excelente y novedosa aportación crítica, que se convierte en paso indispensable para las siguientes aproximaciones críticas a la materia en la península ibérica. No en vano, desbroza las principales líneas de investigación relacionadas con el texto, su situación entre la materia artúrica europea y el género editorial de los libros de caballerías, los principales motivos, los personajes y el manejo de los sucesivos adaptadores de las técnicas traductológicas y narrativas.

Pablo Domínguez Muñoz Universidad de Alcalá 